Original Research

\title{
Attitudes towards COVID-19 vaccination, vaccine hesitancy and intention to take the vaccine
}

Maria CORDINA (iD), Mary A. LAURI (iD), Josef LAURI ID).

Received (first version): 5-Feb-2021

\author{
Published online: 22-Mar-2021
}

\begin{abstract}
Background: The pandemic is at a paradoxical stage, with vaccine roll out initiated but a significantly elevated level of infection and death. Hope for recovery lies in high equitable vaccine uptake.

Objective: The study aimed to: i) explore attitudes and factors influencing attitudes, towards the COVID-19 vaccine amongst people living in Malta, ii) identify the reasons as to why individuals are unsure or unwilling to take the vaccine.

Methods: Two consecutive, short, anonymous online surveys using social media platforms were used to gather data from adult individuals. The first study was open to residents in Malta, while the second study invited international participation. Study 1 consisted of 17 questions inspired by the Theories of Planned Behaviour and Reasoned Action. Study 2 asked participates whether they were willing, unwilling or unsure of taking the vaccine and their reasons for being unsure or unwilling.

Results: A total of 2,529 individuals participated in Study 1 and 834 in Study 2. In both studies respondents were predominantly female having a tertiary education. Over $50 \%$ declared that they were willing to take the vaccine, with males being more willing ( $t=5.83$, $d f=1164.2, p<0.00005)$. Opinions of significant others- family and friends $(r=0.22, p<0.005)$ and health professionals $(r=0.74, p<0.005)$ were associated with willingness to take the vaccine. Vaccine hesitancy was present in the study population with $32.6 \%$ being unsure and $15.6 \%$ declaring that they were not willing to take the vaccine. Females were more likely to be unsure (Chi-squared=14.63, $d f=4$, $\mathrm{p}=0.006$ ). Lack of vaccine safety was the main reason cited for unwillingness to take the vaccine. Predictors for willingness to take the vaccine were: i) The belief that the COVID-19 vaccine will protect the health of the people who take it; ii) Valuing the advice of health professionals regarding the effectiveness of COVID-19 vaccine; iii) Having taken the influenza vaccine last year and; iv) Encouraging their elderly parents to take the vaccine.

Conclusions: COVID-19 vaccination information campaigns should promote group strategies, focusing on emphasising the safety of the vaccine and offer reassurance, especially to women.
\end{abstract}

Keywords

COVID-19 Vaccines; Immunization Programs; Vaccination; Vaccination Refusal; Attitude; Health Knowledge, Attitudes, Practice; COVID19; SARS-CoV-2; Pandemics; Health Belief Model; Cross-Sectional Studies; Malta

\section{INTRODUCTION}

It has been just over a year since the first cases of the Coronavirus SARS-CoV-2, leading to the disease COVID-19, have been identified. Over this period, much has changed in terms of knowledge about the virus and its management. It has, indeed, been a steep learning curve for all involved. ${ }^{1}$ While physical distancing and other preventive measures have become an integral part of daily life for most, the hope for recovery from this pandemic focuses on widespread vaccination against COVID-19. This paper comes at a time when a number of vaccines that have been deemed to be safe and effective by international medicines regulatory bodies are available and vaccine roll out is underway in several countries, although challenges in assessing the efficacy of candidate SARS-CoV-2 vaccines still exist. $^{2-4}$ It is also a time when virus variants have been identified and are causing significant concern. While vaccines are available, there are issues with the supply chain and the world is dealing with an exceedingly high rate

Maria CORDINA. BPharm (Hons.), PhD. Associate Professor Department of Clinical Pharmacology and Therapeutics. WHO Collaborating Centre for Health Professionals Education and Research, Faculty of Medicine and Surgery, University of Malta. Msida (Malta).maria.cordina@um.edu.mt

Mary Anne LAURI. BA (Hons),MSc, PhD, CPsychol. Professor. Department of Psychology, Faculty of Social Well Being, University of Malta. Msida (Malta). mary-anne.lauri@um.edu.mt Josef LAURI. BSc.,MSc, PhD. Professor. Department of Mathematics, Faculty of Science, University of Malta. Msida (Malta). josef.lauri@um.edu.mt of infection and death..$^{5-7}$ This has been described as the pandemic paradox by the WHO regional Director for Europe, Dr Hans Kluge. ${ }^{8}$ Significant challenges are additionally related to vaccine equity, with low and middle income countries struggling to engage in effective vaccination programmes. The World Health Organisation (WHO) has been working hard to address this issue - and a recent study commissioned by the Foundation of the International Chamber of Commerce (ICC), clearly demonstrates that unless there is global access to the vaccine, this would result in not only a moral failure but also an international economic failure. ${ }^{9,10}$

Once an effective population programme is in place, it is essential for vaccine uptake by the population to be as high as possible to enable the attainment of herd immunity. ${ }^{11,12}$ A possible barrier to this could be vaccine hesitancy, which has been defined as "delay in acceptance or refusal of vaccination despite availability of vaccination service. It is complex and context specific, varying across time, place, and vaccines. It is influenced by factors such as complacency, convenience, and confidence"." 9,13 Vaccine hesitancy was identified as one of the ten global health threats of 2019. ${ }^{14}$ A significant factor fuelling vaccine hesitancy in the present pandemic is the current misinfodemic, with social media facilitating the spread of misinformation. ${ }^{15}$ One paper suggested that identifying and correcting information on social media platforms, while important, was not having the desired effect. ${ }^{16}$ Through the 
use of infodemiology, defined as 'the science of distribution and determinants of information in an electronic medium, specifically the Internet, or in a population, with the ultimate aim to inform public health and public policy', WHO has created an infodemiology strategy for the world with the aim of flattening the misinfodemic curve. ${ }^{17,18}$ Trained infodemiology managers, through a specifically developed social media tool, monitor trends, correct misinformation and disseminate evidence-based information on various media channels, online and offline. $^{19}$

The Theory of Planned Behaviour suggests that, whether or not a person will comply with a particular behaviour, in this case taking the COVID-19 vaccine, depends on three major factors. ${ }^{20}$ These factors being: i) the person's attitudes towards the vaccination in general and the COVID-19 vaccine in particular; ii) the attitudes of 'significant others' about the vaccine; iii) the perceived behavioural control which refers to the perceived difficulty in performing the behaviour, that is, taking the vaccine.

All these three factors are influenced by the social representations people have of vaccines. These representations are created and changed by social media. Social media are major determinants of attitudes and behaviour. Moreover, it is well established that attitudes are not directly correlated with behaviour. While individuals may have a positive attitude towards something, they will not necessarily behave in a manner which is consistent with that attitude. ${ }^{21-23}$ Research by Fishbein and Ajzen based on Theory of Reasoned Action found that attitudes of significant others in a person's life have an important effect on whether people comply with performing a particular behaviour. ${ }^{24}$ Therefore, positive health behaviour can be enhanced, if those who are important in a person's life encourage them to do so. Further studies showed that compliance with a health behaviour was predicted even better if self-efficacy and perceived control were considered together with attitudes and subjective norms. ${ }^{25,26}$ In circumstances when people believe that a particular health-related behaviour can bring about a change in their lives and when they believe that they have control over whether or not to perform this behaviour, the likelihood that the person performs this behaviour increases.

Two consecutive studies, informed by the theories outlined above, were conducted. The primary aim of Study 1 was to explore the attitudes, and factors influencing these attitudes, towards the COVID-19 vaccine amongst people living in Malta while Study 2 aimed to identify the reasons as to why individuals were unsure or unwilling to take the vaccine.

\section{METHODS}

\section{Study design}

In terms of Study 1 a cross-sectional web-based study design was employed to gather data about attitudes and behaviour towards the COVID 19 vaccine. The anonymous questionnaire was disseminated through the most common social media platforms such as Facebook, Messenger, and WhatsApp. Respondents were encouraged to share as widely as possible on their own social media apps. Inclusion criteria were that respondents resided in Malta and were over 16 years of age.

The same methodology was employed for Study 2, however this was open to an international population not just individuals residing in Malta.

In both studies, the researchers identified themselves as being affiliated with the University of Malta and respondents were informed that the questionnaire was anonymous, voluntary and that it was very short, taking up only very few minutes of their time. The questionnaires were initially designed in the English language and then translated to the Maltese language by a translation expert. The Maltese version was back translated and verified as being correct in both languages. The questionnaire was designed to have the English version of the question, followed by the Maltese version. This design, based on the Skopos Theory, has been found to be the most appropriate, since the Maltese people tend to code switch between the Maltese and English language. ${ }^{27}$ The studies utilized google forms to gather the data. Prior to initiating the studies, the questionnaires were pilot tested with individuals from different backgrounds using a variety of devices.

In Study 1, data was collected using a questionnaire made up of 17 questions. It was structured as follows: Demographics: Gender, age, marital status, educational level, country of residence, whether respondents where health workers, suffered from chronic disease and whether they took the influenza vaccine the previous year. While the questionnaire was clearly addressed to people residing it Malta, it was possible that people residing in other countries would still answer it. The question asking respondents to indicate their country of residence was inserted to address this issue. Any responses from individuals indicating their country of residence was not Malta were discarded.

Questions to determine attitudes towards COVID-19, about the vaccine, vaccine hesitancy and factors that could influence these attitudes were loosely based on the Theory of Planned Behaviour. ${ }^{20}$ These included whether participants engaged in preventive behaviour, whether they believed that COVID-19 vaccine will help protect the health of the people who get it; whether the opinion of family and friends was important in their decision to take the vaccine; whether they valued the advice of health professionals regarding the effectiveness of the COVID-19 vaccine; how much they believed that they know about COVID-19 and how much news and information they had seen and heard about COVID-19. The responses were measured on a Likert scale with 1 being strongly disagree/not at all and 10 being strongly agree/very much.

The intention regarding participants' willingness to accept the COVID -19 vaccine and whether they demonstrated vaccine hesitancy was explored using likert scales and binary questions. These included: whether they intended to take the COVID-19 vaccine when it became available (1 being definitely no and 10 being definitely yes); whether they were willing to give COVID-19 vaccine to their children and whether they would encourage their elderly parents to 
take the COVID-19 vaccine. In the latter two questions the responses were categorical: Yes/No/Unsure/Not applicable.

For Study 2 basic demographics of gender, age, educational level and country of residence were collected. Respondents were asked whether they intended to take COVID-19 vaccine when it becomes available with possible responses being yes, no, unsure. Those that answered no or unsure where invited to give reasons for their choice, either select from a predetermined set of responses and/or list their own reasons. Respondents were free to choose any number of reasons.

Data for Study 1 was gathered between 30/10/2020 and $16 / 11 / 2020$ and data for Study 2 was gathered between $26 / 10 / 2020$ and $26 / 11 / 2020$

\section{Statistical approach}

Data was analysed using the statistical package $R^{28}$ Descriptive statistics were generated to provide a demographic profile of respondents. Mean/median scores and quartiles were generated for the Likert scale variables to identify the respondents' attitudes towards the COVID19 vaccine and their degree of willingness to take the vaccine. T-tests and one-way ANOVA tests, followed by post-hoc pairwise t-tests with $p$-values corrected for multiple comparisons using the Benjamini-Hochberg (BH) correction, were used to determine the relationship between demographics and responses related to attitudes and willingness as measured by the Likert scale variables. The Likert variable measuring willingness to take vaccine was regressed against the other scale variables and the key demographics. The main predictors were then identified as the ones for which this multivariate regression gave significant beta coefficients. Pearson correlation coefficients were calculated to determine which factors could influence respondents' decision to take the vaccine. Chi-squared statistics were used in Study 2 to determine associations between demographics and willingness to take the COVID-19 vaccine and reasons for being unsure or unwilling to take the COVID-19 vaccine. The level of significance was set at $p<0.05$

\section{Controlling for duplicates and sampling bias}

The only manner in which google forms allows for control of duplicate responses is to allow it to record the email of the respondent. Since the questionnaires were anonymous, this was not possible. The data was reviewed and cleaned prior to analysis.

The methodology employed, whereby the questionnaires were initially disseminated by the investigators, could lead to selection bias, whereby respondents would pertain to a demographic similar to the investigators. This was mitigated by employing snowball sampling following the initial volunteer sampling.

The study received ethical clearance by the University of Malta Ethics Research Committee UREC. (Ethics ID 644322092020)

\section{RESULTS}

A total of 2529 individuals participated in the first study as illustrated in Table 1 . The sample participants were

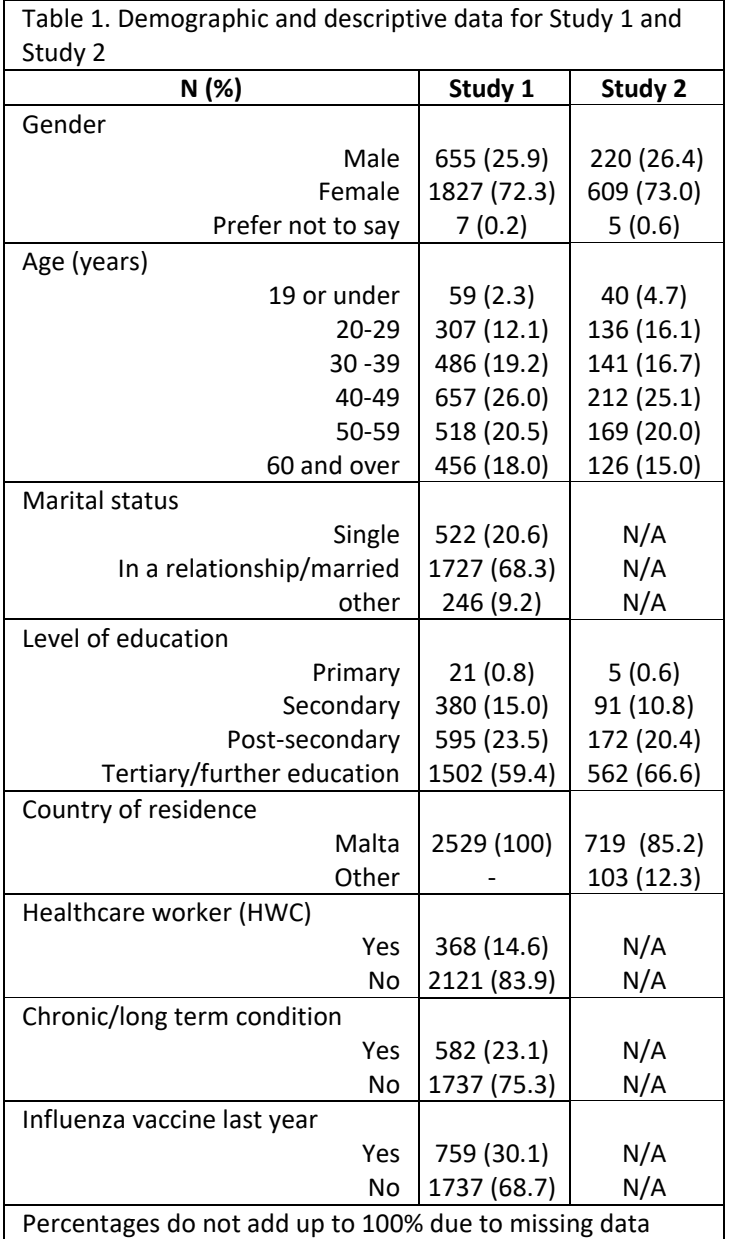

predominantly female $(72.3 \%)$, with nearly $60 \%$ having a tertiary education. All age groups had a good representation.

The second study, the demographics of which are presented in Table 1, was primarily targeted at finding out the reasons why participants were against or unsure of taking the vaccine. There were 843 respondents with a similar general profile to the first study. Of the participants, $12.3 \%$ were international respondents. Just over half (51.0\%) of the participants stated that they were willing to take the vaccine, $32.6 \%$ were unsure and $15.6 \%$ were not willing to take the vaccine.

\section{Study 1}

Attitudes towards COVID-19 vaccine and influencing factors

The results presented in Table 2 relating to attitudes towards the COVID-19 vaccine and relevant influencing factors, demonstrates that in most questions, $50 \%$ of respondents gave a score of 8 or above (score of 1 indicated an absolute negative response and a score of 10 an absolute positive response).

Welch t-tests indicated that women were more likely than men to engage in preventive behaviours such as mask/visor wearing, handwashing/sanitizing and social distancing $(t=8.97, d f=949.14, p<0.00005)$ but to believe less that the COVID-19 vaccine will help protect the health of the people who take it $(t=-3.6479, d f=1147.6, p=0.0003)$. Men were more likely to value the advice of health care professionals regarding the effectiveness of the COVID-19 vaccine 


\begin{tabular}{|c|c|c|c|c|c|c|}
\hline Attitude towards COVID-19 Vaccine & Mean (SD) & Minimum & Q1 & Median & Q3 & Maximum \\
\hline I would take the Covid-19 vaccine when it becomes available & $6.85(3.19)$ & 1 & 5 & 8 & 10 & 10 \\
\hline How much would you say that you know about COVID-19 & $7.38(1.67)$ & 1 & 6 & 8 & 8 & 10 \\
\hline How much news and information have you seen and heard about COVID-19 & $8.46(1.47)$ & 1 & 8 & 9 & 10 & 10 \\
\hline $\begin{array}{l}\text { I engage in preventive behaviour(wearing mask/visor, social distancing, } \\
\text { frequent hand washing, sanitiser use) }\end{array}$ & $9.28(1.24)$ & 1 & 9 & 10 & 10 & 10 \\
\hline I believe that the COVID-19 vaccine will help protect the people who take it. & $7.50(2.59)$ & 1 & 6 & 8 & 10 & 10 \\
\hline $\begin{array}{l}\text { The opinion of family and friends is important in my decision to take COVID-19 } \\
\text { vaccine }\end{array}$ & $4.82(3.10)$ & 1 & 2 & 5 & 8 & 10 \\
\hline $\begin{array}{l}\text { I value the advice of health professionals regarding the effectiveness of the } \\
\text { COVID-19 vaccine }\end{array}$ & $8.00(2.44)$ & 1 & 7 & 9 & 10 & 10 \\
\hline
\end{tabular}

$(t=2.3364, d f=1183.8, p=0.02)$ and were more likely to be willing to take the vaccine $(t=5.83, d f=1164.2, p<0.00005)$.

\section{Willingness to take the COVID-19 vaccine}

The key Likert variable was the respondents' score to the statement "I will take the Covid-19 vaccine when available" which will be referred to as the variable "WillTake". The mean score of "WillTake" among all respondents was 6.85 $\mathrm{SD}=3.19$ with a median of 8 indicating that $50 \%$ of respondents scored 8 and over. This implies a strong willingness to take the vaccine

There was a strong correlation between participants who believed that vaccination will help protect people against COVID-19 and willingness to take vaccine $(r=0.79, p<0.005)$. There was also a significant relationship between willingness to take the vaccine and giving importance to the opinions of family and friends. Pearson's correlation coefficient $r$ for the relationship between willingness to take the vaccine and giving importance to the opinion of family and friends was quite significant $(r=0.22, p<0.005)$, but an even more significant relationship was found between willingness to take the vaccine and the importance given to the advice of health professionals $(r=0.74, p<0.005)$.

A one-way ANOVA test of the scale variable "WillTake" with age showed significant differences between the age groups
$(F(5,2420)=3.34, p=0.005)$. To ascertain between which age categories this difference was significant, ANOVA was followed by post-hoc pairwise t-tests with $p$-values corrected for multiple comparisons using $\mathrm{BH}$ correction. Results showed that respondents over the age of 60 were more willing to take the COVID-19 vaccine as compared to those between the ages of 30-39 $(p<0.02)$ and those between $40-49$ years of age $(p<0.01)$. The one-way ANOVA of "WillTake" by level of education indicated no significant differences between the educational categories $(F(3,2476)=2.15, p=0.09)$, although there was a very strong difference among the educational categories in the belief that the COVID-19 vaccine will protect against the virus $(F(3,2477)=8.01, \quad p<0.00002)$. Those having a tertiary education were more likely to believe that the vaccine will help protect the health of the people who take it, than those whose highest qualification was secondary $(p=0.003)$ and post-secondary education $(p=0.0003)$.

\section{Predictors of willingness to take COVID-19 Vaccine}

Regression analysis was conducted to determine predictors of willingness to take the COVID-19 vaccine. As indicated above, the variable "WillTake" showed a strong willingness by most of the respondents to take the vaccine. A good indication of this positive attitude towards the vaccine was also shown by the fact that more than half of the respondents $(56 \%, n=1196)$ would encourage their elderly

\begin{tabular}{|c|c|c|}
\hline Variable & Beta & p-value \\
\hline Knows about COVID-19 & -0.021887 & 0.41243 \\
\hline News and Information seen about COVID-19 & -0.013112 & 0.65409 \\
\hline I engage in preventative behaviour & -0.028971 & 0.35847 \\
\hline Believes that COVID-19 vaccines will help protect the health of the people who take it & 0.228807 & $<0.0005$ \\
\hline Opinion of family and friends important in decision to take COVID-19 vaccine & 0.016498 & 0.20025 \\
\hline Value the advice of healthcare professionals re effectiveness of COVID-19 vaccine & 0.236737 & $<0.0005$ \\
\hline Is a health worker & 0.050775 & 0.63272 \\
\hline Has a chronic condition & 0.008421 & 0.92905 \\
\hline Sex male & 0.176704 & 0.5311 \\
\hline Age $20-29$ & 0.208428 & 0.62593 \\
\hline Age 30-39 & 0.301352 & 0.45829 \\
\hline Age $40-49$ & 0.284435 & 0.48095 \\
\hline Age $50-59$ & 0.301576 & 0.45694 \\
\hline Age 60 and over & 0.427421 & 0.30803 \\
\hline Education primary & 0.356446 & 0.41913 \\
\hline Education secondary & -0.030026 & 0.81031 \\
\hline Education tertiary/further & -0.077934 & 0.40024 \\
\hline Had flu jab last year & 0.276383 & $<0.0020$ \\
\hline Unsure if give COVID-19 vaccine to children & 2.036730 & $<0.0005$ \\
\hline Willing to give COVID-19 vaccine to children & 4.241188 & $<0.0005$ \\
\hline Unsure if encourage COVID-19 vaccine to elderly parents & 0.285070 & 0.08969 \\
\hline Willing to encourage COVID-19 vaccine to elderly parents & 1.065202 & $<0.0005$ \\
\hline
\end{tabular}




\section{Reasons for not wanting to take COVID-19 Vaccine}

I do not think that it will give the necessary immunity

I have had a bad experience with vaccines

COVID-19 is just like any other flu that will pass

I am afraid of injections

I believe in natural and traditional remedies

I am against vaccination in general

I think COVID-19 vaccine may not be safe
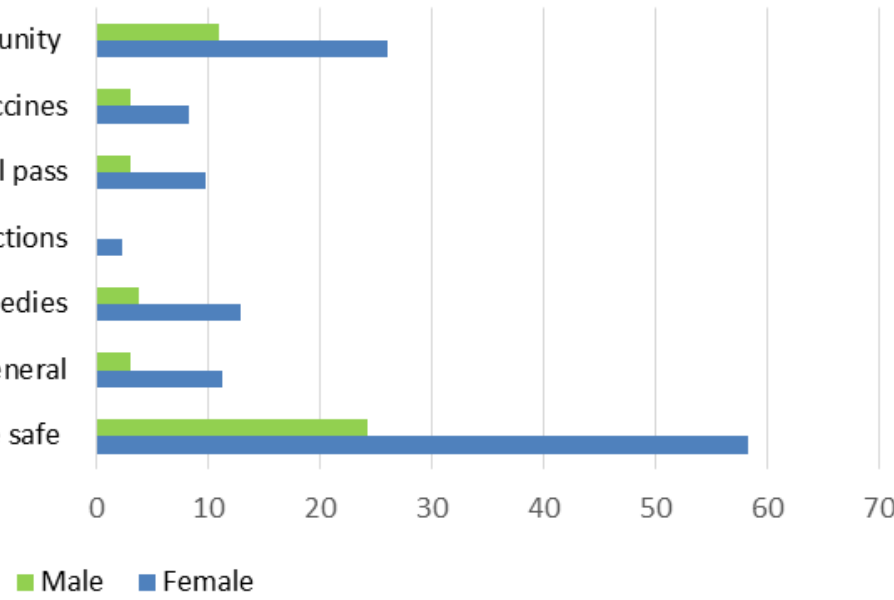

Figure 1. Study 2 - Reasons given by respondents who were unwilling to take COVID -19 vaccine presented as percentages $(\mathrm{N}=132)$

parents to take the vaccine, $32 \%(n=674)$ were unsure and only $12 \%(n=263)$ of those who answered would not. As expected, respondents were more cautious in declaring their willingness to give the vaccine to their children: of those who answered the question $43 \%(n=654)$ said 'yes', $36 \%(558)$ were unsure and $21 \%(n=321)$ said 'no'.

A regression analysis was carried out to determine the best predictors of willingness to take the vaccine. The variable 'WillTake' was the predicted variable while the main demographic variables and the other scale variables were the predictors.

The regression model obtained explained $83 \%$ of the variance $\left(R^{2}=0.834\right)$. Residual standard error was 1.355 on 1351 degrees of freedom. Table 3 lists the beta coefficients of the predictors of willingness to take the vaccine.

\section{Study 2}

Descriptive data of the study population $(\mathrm{N}=843)$ for Study 2 is presented in Table 1. Of the participants, $73 \%$ were females and $66.6 \%$ had a tertiary education. The reasons for refusing to take the vaccine or being unsure are illustrated as percentages in Figure 1 and Figure 2. The main issue for not wanting to take the vaccine is related to the belief that it may not be safe $(85.2 \%, \mathrm{~N}=132)$. Oddly, fear of injections was cited as the major reason for being unsure of taking the vaccine $(82.5 \%, \mathrm{~N}=275)$ followed by $56 \%$ who declared that they wanted more information about the vaccine and $50.1 \%$ who would not be willing to be among the first to take the vaccine.

When studying willingness to take the vaccine in terms of demographics, males were more willing to take the vaccine, while females were more likely to declare that they were unsure (chi-square $=14.63, d f=4, p=0.006$ ). Different age groups also gave statistically different responses with those between the ages of 40 to 49 years old being more likely to state that they were unsure whether to take the vaccine while those who were 60 years and over being more likely to say that they intended to take the vaccine (chisquare $=23.99, d f=10, p=0.007$ ).

\section{Reasons for being unsure of taking COVID-19 vaccine}

I have had a bad experience with vaccines

I am afraid of injections

I am not sure it will give the necessary immunity

I would want more information about the vaccine

I would want to see whether the number of infected...

I am afraid that it will have unknown side effects

I would not like to be among the first who take it

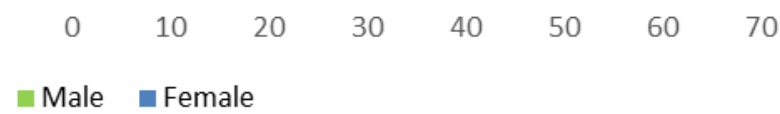

80

Figure 2. Study 2 - Reasons for being unsure whether to take vaccine presented as percentages $(N=275)$ 
Table 4. Study 2 - Additional reasons for not refusing to take vaccine and being unsure of taking COVID-19 vaccine

- Too short a time for development and testing (10 comments)

- Long term repercussions (2 comments)

- Do not trust system

- Political game

- I want to build my own immunity

- Harmful substance in vaccine (2 comments)

- Vaccine not reliable

- Have a condition/cancer (2 comments)

- Do not believe COVID is a threat

- Vaccine will not help

- Vaccine is a money-making venture

- Not safe with lower efficacy

- I am not a guinea pig

The predetermined reasons given for being unsure or unwilling to take the vaccine did not significantly differ between respondents. The only exception was being unwilling to take the vaccine due to fear of injections: females were more likely to give this reason then males (chi-square $=7.43, \mathrm{df}=1, \mathrm{p}=0.0064$ ) and Maltese residents were more likely to give this reason when compared to international respondents (chi-square $=7.87, \mathrm{df}=1, \mathrm{p}=0.005$ ).

Additional comments were provided by individuals who were unwilling or unsure of taking the vaccine presented in Table 4.

\section{DISCUSSION}

The two consecutive studies conducted sought to demonstrate willingness to take the COVID-19 vaccine, predictors of vaccine uptake and possible reasons for vaccine hesitancy. The present studies have demonstrated encouraging results in terms of willingness for vaccine uptake, with over $50 \%$ indicating a very strong willingness to take the vaccine and $32.6 \%$ being unsure, at a time when information about the safety and efficacy of the vaccines was rather limited. The data collection period also coincided with Malta entering into the second wave of the pandemic. Study 2 identified that $15.6 \%$ were categorically against taking the vaccine. The results for vaccine uptake are in line with to international studies. Willingness to take the vaccine from a European study was reported at $73.9 \%$, the UK Oxford study reported $71.7 \%$, a global survey of 19 countries was $71.5 \%$ and in the USA $52 \%$ were very likely and $27 \%$ somewhat likely to take the vaccine. ${ }^{29-32}$ Data for refusal to take the vaccine was within the range of internationally reported numbers. ${ }^{29,33-36}$

Vaccine hesitancy is related to attitudes. ${ }^{13}$ Participants who were unsure whether or not to be vaccinated wanted more information about the vaccine. The availability of increased information with regards to safety and efficacy of the vaccines is however rivalled by the misinformation circulating on the social media. Those who were categorical in their intention not to take the vaccine had a different set of attitudes which exhibited a general lack of faith in vaccines. This is especially evident in the data presented in Figures 1 and 2 and Table 4 .

The attitudes of significant others were identified as being an important factor influencing vaccine uptake. A strong positive correlation was found between willingness to take the vaccine and giving importance to the opinion of family

Reasons for being unsure

- Planned pregnancy/fear of being pregnant (3 comments)

- Prefer vaccine that has been tested

- Allergic to latex

- Afraid of long-term effects (2 comments)

- Not convinced of number of infected reported

- Never took vaccine before

- Not convinced of the safety standards of vaccine

- How long will immunity last?

- Length of testing too short

- Something that nobody knows about

- Depends where it has been developed

- Would like to know how effective it is

and friends as well as valuing the advice of health care professionals. Males were more likely than females to value the advice of health care professionals regarding the effectiveness of the vaccine. The results reflect this argument and support the Theory of Reasoned Action and the Theory of Planned Behaviour. ${ }^{20,24}$

Respondents believed that they were very knowledgeable and were well informed through the media about COVID-19 as seen in Table 2. Interestingly these two factors did not feature as predictors of vaccine uptake. While copious amounts of information are available, especially on social media, a lot may be misleading, bias or untrue, fuelling vaccine hesitancy. The World Health Organization is doing its utmost to identify and address misinformation however, increased responsibility and appropriate and effective campaigns are still necessary globally. ${ }^{37}$ Positive attitudes toward vaccination can be encouraged through media advocacy involving the strategic use of social media for advancing a social or public policy initiative such as vaccination. Through advocacy, decreasing vaccine hesitancy and promoting vaccination is no longer seen as an issue concerning the individual but rather a societal concern placed at the top of the public agenda.

Gender has been demonstrated to be a significant issue during this pandemic. The present study showed that while women were more likely to engage in preventive behaviour as demonstrated in other studies, they were less likely to believe that the vaccine will protect the health of the people who take it and were less willing than men to take the vaccine. ${ }^{38-40}$ The latter was evident in both studies with more females declaring that they are unsure of taking the vaccine. This lack of conviction by women has been identified by a number of other studies. ${ }^{41,42}$ A study conducted in eight OECD countries which undertook a detailed analysis regarding gender-based issues pertaining to the pandemic demonstrated the same results and recommended gender-based public health policies and communication. ${ }^{43}$ Taking a vaccine may be considered a risk and studies about decision making and risk taking among men and women based on a psychological assessment of risk personality show that women are more cautious and take longer to evaluate risk. ${ }^{44,45}$ Oddly, the fear of injections was a significant reason as to why females in Malta were unsure of taking the vaccine. This reason was found to be of minimal concern in a European study. ${ }^{29}$

Respondents between the ages of 30 and 49 appear to be less willing to take the vaccine than those over 60 years of 
age. These findings are supported by other studies in the US, UK and Ireland. ${ }^{42,46}$ The US study analysed national trends, between April and December 2020, in the public's likelihood of getting the vaccine and reported that those aged over 65 are more willing to take the vaccine than those between $18-49$ years. ${ }^{46}$ Similarly the UK reported that those over 65 were less resistant to taking the vaccine and in Ireland those who were more resistant were between the ages of 25 and $44{ }^{42}$ These results could be indicative that the message regarding the vulnerability of the elderly to COVID-19 is clear and has been received.

While educational background had no influence on willingness to take the vaccine, those with a tertiary education were more likely to believe that the vaccine will protect the people who take it. Conversely, in US studies people with a bachelor's degree or higher were more likely to be willing to get vaccinated. ${ }^{46,47}$

The best predictors obtained by regressing willingness to take the COVID-19 vaccine on the other Likert scale variables and the main demographic factors largely confirmed results obtained from pairwise correlations, chisquared tests, ANOVAs and t-tests. It is to be expected that not wanting to give the vaccine to one's children and elderly relatives are strong predictors of not willing to take the vaccine oneself. Having taken the flu vaccine last year is a strong predictor of willingness to take the COVID-19 vaccine. The latter would seem to indicate that a positive attitude towards the COVID-19 vaccine goes along with a positive view towards vaccination in general. The fact that willingness to take the vaccine is strongly predicted by belief that it will help protect the health of the people who take it and also by valuing the advice of health professionals would seem to indicate that vaccine hesitancy is strongly related to mistrust in medical evidence.

Vaccine hesitancy is more of a continuum than a binary decision. At one end there are those who accept all vaccines with no doubts, at the other end are those who completely refuse vaccination and then there is a heterogeneous group in the middle of the continuum. These tend to delay vaccination or accept vaccination but are unsure in doing so. ${ }^{13}$ Social psychological theories propose that it is easier to change the attitudes if they are within the 'latitude of acceptance'. ${ }^{23,48-51}$ For this reason campaigns are most effective when targeteding this heterogeneous group of people in the middle of the continuum. ${ }^{52}$ Campaigns are unlikely to change attitudes of those who are directly opposed to vaccination and therefore these should not be targeted initially. Communication campaigns promoting group strategies can encourage cohorts of people to move from knowledge to action.
The main strength of this study was the large number of respondents, especially in Study 1 . Additionally, Study 2 was found to clearly support and complement the findings of study 1 . However, the results need to be interpreted with caution due to some limitations. These are crosssectional studies conducted on social media. The responses therefore exclude those who do not use social media. There respondents are predominantly female and have a tertiary education and as such are not representative of the general population. Response bias in favour of those having a positive attitude towards the vaccine could have also been present. The studies were conducted at a time where the health landscape was, and still is, extremely fluid with much more limited information about COVID-19 and the COVID-19 vaccines. Responses are therefore reflective of the information available at the time.

\section{CONCLUSIONS}

A generally positive attitude towards COVID-19 vaccine has been reported and clear predictors of willingness to take the vaccine have been identified. The opinion of significant others, such as family, friends and healthcare professionals were positively associated with willingness to take the vaccine A degree of vaccine hesitancy was present, primarily in women and mainly linked to lack of conviction about vaccine safety. Therefore, information campaigns should focus on providing more information about COVID19 vaccine safety, reassuring the population, especially women. The positive link identified between the opinions of significant others and vaccine uptake, indicates that vaccine strategies targeted at groups of individuals such as work groups and leisure groups are likely to be more effective.

\section{CONFLICT OF INTEREST}

None.

\section{FUNDING}

None.

\section{AUTHOR ROLES (CRediT)}

Conceptualization. MC, MAL, JL.

Data curation. JL.

formal analysis. JL.

Investigation. MC, MAL, JL.

Methodology. MC, MAL, JL.

Project administration. MC.

Validation. JL.

Visualization. MC, MAL, JL.

Writing - original draft. MC, JL.

Writing - review \& editing. MC, MAL, JL.

References

1. World Health Organisation. Corona Virus Disease (COVID-19) Pandemic. https://www.who.int/emergencies/diseases/novel-coronavirus-2019?gclid=CiwKCAiAgc-AB hA7EiwAjevj6mGRzsdtzqbpPQn8DNH3x2WdMmdAG RIGyG4xdUt4nKnXgMwoXdYRoCVDEQAvD BwE (accessed Feb 4, 2021)

2. Our World in Data. Corona Virus (COVID-19) Vaccinations. https://ourworldindata.org/covid-vaccinations (accessed Feb $4,2021)$ 
3. European Centre for Disease Control and Prevention (ECDC). Overview of COVID-19 vaccina-tion strategies and vaccination deployment plans in EU/EEA technical report. https://www.ecdc.europa.eu/en/publications-data/overviewimplementation-covid-19-vaccination-strategies-and-vaccine-deployment (accessed Feb 4, 2021)

4. Hodgson SH, Mansatta K, Mallett G, Harris V, Emary KRW, Pollard AJ. What defines an efficacious COVID-19 vaccine? A review of the challenges assessing the clinical efficacy of vaccines against SARS-CoV-2. Lancet Infect Dis. 2021;21(2):e26-e35. https://doi.org/10.1016/s1473-3099(20)30773-8

5. European Centre for Disease Control and Prevention (ECDC). Risk related to SARS-CoV-2 var-iants of concern in EU /EEA. First update. https://www.ecdc.europa.eu/en/publications-data/covid-19-risk-assessment-spread-new-variantsconcern-eueea-first-update?fbclid=IwAR0UPcRtV6JOyTu3vCOICv3KOgQneGJ Uyw3XBQbNe2TvaReFcaDnKX21Bc (accessed Feb 4, 2021)

6. World Health Organisation. Corona Virus Disease (COVID-19) Dashboard. https://covid19. who.int/?gclid=CiwKCAiAgcABhA7EiwAjev-jyX27VnkHYh Muqsztk1IApJ2DI8LWEyMneN01KfS4x H3Z JtbMZxoC 8sQAvD BwE (accessed Feb 2021)

7. European Centre for Disease Control and Prevention (ECDC). COVID-19 Situation Dashboard. https://qap.ecdc.europa.eu/public/extensions/COVID-19/COVID-19.html\#global-overview-tab (accessed Feb 4, 2021)

8. Kluge $\mathrm{H}$. The pandemic paradox: hope and hardship in equal measure. World Health Organi-sation, Regional Office for Europe 2021. https://www.euro.who.int/en/media-centre/sections/statements/2021/statement-update-on-covid-19-thepandemic-paradox-hope-and-hardship,-in-equal-measure (accessed Feb 4, 2021)

9. Swaminathan S. The WHO's chief scientist on a year of loss and learning. Nature. 2020;588(7839):583-585. https://doi.org/10.1038/d41586-020-03556-y

10. Cakmakli C, Demiralp S, Kalemli-Ozcan S, Yesiltas S, Yildirim MA. The economic case for global vaccinations: An epidemiological model with international production networks. ICC Research Foundation commissioned study. https://iccwbo.org/publication/the-economic-case-for-global-vaccinations/ (accessed Feb 4, 2021)

11. Fontanet A, Cauchemez S. COVID-19 herd immunity: where are we?. Nat Rev Immunol. 2020;20(10):583-584. https://doi.org/10.1038/s41577-020-00451-5

12. Ashby B, Best A. Herd immunity. Curr Biol. 2021;31(4):R174-R177. https://doi.org/10.1016/j.cub.2021.01.006

13. MacDonald NE; SAGE Working Group on Vaccine Hesitancy. Vaccine hesitancy: Definition, scope and determinants. Vaccine. 2015;33(34):4161-4164. https://doi.org/10.1016/j.vaccine.2015.04.036

14. World Health Organisation. Ten threats to global health in 2019. https://www.who.int/news-room/spotlight/ten-threats-toglobal-health-in-2019 (accessed Feb 4, 2021)

15. Kim HK, Ahn J, Atkinson L, Kahlor LA. Effects of COVID-19 information on information seeking, avoidance and processing: A multi-country comparative study. Sci Comm. 2020;42(5):586-615. https://doi.org/10.1177\%2F1075547020959670

16. Chou WS, Gaysynsky A, Vanderpool RC. The COVID-19 Misinfodemic: Moving Beyond Fact-Checking. Health Educ Behav. 2021;48(1):9-13. https://doi.org/10.1177/1090198120980675

17. Eysenbach G. Infodemiology and infoveillance: framework for an emerging set of public health informatics methods to analyze search, communication and publication behavior on the Internet. J Med Internet Res. 2009;11(1):e11. https://doi.org/10.2196/imir.1157

18. World Health Organisation. Early Al supported Response with Social Listening (EARS). https://whoinfodemic.citibeats.com/ (accessed Feb 4, 2021)

19. World Health Organisation. Infodemic manager training. https://www.who.int/teams/risk-communication/infodemicmanagement/1st-who-training-in-infodemic-management (accessed Feb 4, 2021)

20. Ajzen, I. From intentions to actions: A theory of planned behaviour. In: Kuhn J, Beckman J, eds. Action Control: from cognition to behaviour. New York: Springer Verlag;1985.

21. LaPiere RT. Attitudes vs Actions. 1934. Int J Epidemiol. 2010;39(1):7-11. https://doi.org/10.1093/ije/dyp398

22. Wicker AW. Attitudes versus actions: The relationship of verbal and overt behavioural responses to attitude objects. J Soc Issues. 1969:25(4);41-78. https://doi.org/10.1111/j.1540-4560.1969.tb00619.x

23. Crano WD, Prisli R. Attitudes and persuasion. Annu Rev Psychol 2006:57;345-374. https://doi.org/10.1146/annurev.psych.57.102904.190034

24. Fishbein M, Ajzen I. Beliefs, attitude, intention and behaviour: An introduction to theory and research. Reading, MA: Addison-Wesley 1975. https://people.umass.edu/aizen/f\&a1975.html (accessed Feb 4, 2021)

25. Ajzen I. Models of human social behaviour and their application to Health. Psychol Health. 1998:13(4);735-739. https://doi.org/10.1080/08870449808407426

26. Beck L, Ajzen I. Predicting dishonest actions using the theory of planned behaviour. J Res Person. 1991;25(3):285-301 https://doi.org/10.1016/0092-6566(91)90021-H

27. Du X. A Brief Introduction of Skopos Theory. Theory Pract Lang Stud. 2012;2(10):2189-2193. https://doi.org/10.4304/TPLS.2.10.2189-2193

28. R Core Team. R: A language and environment for statistical computing. R Foundation for Sta-tistical Computing, Vienna, Austria 2020. https://www.R-project.org/ (accessed Feb 4, 2021)

29. Neumann-Böhme S, Varghese NE, Sabat I, et al. Once we have it, will we use it? A European survey on willingness to be vaccinated against COVID-19. Eur J Health Econ. 2020;21(7):977-982. https://doi.org/10.1007/s10198-020-01208-6

30. Freeman D, Loe BS, Chadwick A, et al. COVID-19 vaccine hesitancy in the UK: the Oxford coronavirus explanations, attitudes, and narratives survey (Oceans) II. Psychol Med. 2020;1-15. https://doi.org/10.1017/s0033291720005188

31. Lazarus JV, Ratzan SC, Palayew A, et al. A global survey of potential acceptance of a COVID-19 vaccine [published correction appears in Nat Med. 2021 Jan 11;:]. Nat Med. 2021;27(2):225-228. https://doi.org/10.1038/s41591-020-1124-9 
32. Khubchandani J, Sharma S, Price JH, Wiblishauser MJ, Sharma M, Webb FJ. COVID-19 Vaccination Hesitancy in the United States: A Rapid National Assessment. J Community Health. 2021;46(2):270-277. https://doi.org/10.1007/s10900$\underline{020-00958-x}$

33. Detoc M, Bruel S, Frappe P, Tardy B, Botelho-Nevers E, Gagneux-Brunon A. Intention to participate in a COVID-19 vaccine clinical trial and to get vaccinated against COVID-19 in France during the pandemic. Vaccine. 2020;38(45):70027006. https://doi.org/10.1016/j.vaccine.2020.09.041

34. Faasse K, Newby J. Public Perceptions of COVID-19 in Australia: Perceived Risk, Knowledge, Health-Protective Behaviors, and Vaccine Intentions. Front Psychol. 2020;11:551004. https://doi.org/10.3389/fpsyg.2020.551004

35. COCONEL Group. A future vaccination campaign against COVID-19 at risk of vaccine hesitancy and politicisation. Lancet Infect Dis. 2020;20(7):769-770. https://doi.org/10.1016/s1473-3099(20)30426-6

36. Ward JK, Alleaume C, Peretti-Watel P; COCONEL Group. The French public's attitudes to a future COVID-19 vaccine: The politicization of a public health issue. Soc Sci Med. 2020;265:113414. https://doi.org/10.1016/i.socscimed.2020.113414

37. World Health Organisation. Citibeats Malta. https://whoinfodemic.citibeats.com/country/mlt?cat=7CYMF9PJ2hQ7oJ2GNoTkWE\&fbclid=IwAR2hDk5MI0DRXR2aasGZ 2Ddv51p91b qJ4ZUsI0XQQZ78gGB0AwzPe4vnDE (accessed Feb 4, 2021)

38. Fisher KA, Bloomstone SJ, Walder J, Crawford S, Fouayzi H, Mazor KM. Attitudes Toward a Potential SARS-CoV-2 Vaccine : A Survey of U.S. Adults. Ann Intern Med. 2020;173(12):964-973. https://doi.org/10.7326/m20-3569

39. Callaghan T, Moghtaderi A, Lueck JA, et al. Correlates and disparities of intention to vaccinate against COVID-19. Soc Sci Med. 2021;272:113638. https://doi.org/10.1016/j.socscimed.2020.113638

40. Khubchandani J, Saiki D, Kandiah J. Masks, gloves, and the COVID-19 pandemic: Rapid assessment of public behaviours in the United States. Epidemiologia. 2020;1(1):16-22; https://doi.org/10.3390/epidemiologia1010004

41. Wong LP, Alias H, Wong PF, Lee HY, AbuBakar S. The use of the health belief model to assess predictors of intent to receive the COVID-19 vaccine and willingness to pay. Hum Vaccin Immunother. 2020;16(9):2204-2214. https://doi.org/10.1080/21645515.2020.1790279

42. Murphy J, Vallières F, Bentall RP, et al. Psychological characteristics associated with COVID-19 vaccine hesitancy and resistance in Ireland and the United Kingdom. Nat Commun. 2021;12(1):29. https://doi.org/10.1038/s41467-020-20226-9

43. Galasso V, Pons V, Profeta P, Becher M, Brouard S, Foucault M. Gender differences in COVID-19 attitudes and behavior: Panel evidence from eight countries. Proc Natl Acad Sci U S A. 2020;117(44):27285-27291. https://doi.org/10.1073/pnas.2012520117

44. Byrnes JP, Miller DC. Gender differences in risk taking; A meta-analysis. Psychol Bull 1999;125(3):367-383. https://doi.org/10.1037/0033-2909.125.3.367

45. Inglehart R. Norris $P$. The developmental theory of the gender gap: women's and men's voting behavior in global perspective. Int Polit Sci Rev 2000:21(4);441-463. https://doi.org/10.1177\%2F0192512100214007

46. Szilagyi PG, Thomas K, Shah MD, et al. National Trends in the US Public's Likelihood of Getting a COVID-19 VaccineApril 1 to December 8, 2020. JAMA. 2020;325(4):396-398. https://doi.org/10.1001/jama.2020.26419

47. Guidry JPD, Laestadius LI, Vraga EK, et al. Willingness to get the COVID-19 vaccine with and without emergency use authorization. Am J Infect Control. 2021;49(2):137-142. https://doi.org/10.1016/i.ajic.2020.11.018

48. O'Keefe DJ. Persuasion: Theory and Research. Newbury Park CA: Sage;1990.

49. Sherif CW. Social categorization as a function of latitude of acceptance and series range. J Abnorm Soc Psychol. 1963;67:148-156. https://doi.org/10.1037/h0043022

50. Johnson BT, Eagly AH. Effects of involvement on persuasion: A meta-analysis. Psycho Bull.1989:106(2);290-314. https://doi.org/10.1037/0033-2909.106.2.290

51. Sherif $\mathrm{M}$, Hovland $\mathrm{Cl}$. Social judgment: Assimilation and contrast effects in communication and attitude change. New Haven: Yale University Press; 1961.

52. Brinol P, Rucker DD, Petty RE. Naïve theories about persuasion. Implications for information processing and consumer attitude change. Int J of Advert 2015:34(1):85-106 https://doi.org/10.1080/02650487.2014.997080 